\title{
Regional, temporal and fine-scale spatial variation in Weddell seal diet at four coastal locations in east Antarctica
}

\author{
Samantha Lake ${ }^{1,2,3, *}$, Harry Burton ${ }^{1}$, John van den Hoff ${ }^{1}$ \\ ${ }^{1}$ Australian Antarctic Division, Channel Highway, Kingston 7050, Tasmania, Australia \\ ${ }^{2}$ Institute of Antarctic and Southern Ocean Studies, School of Maths and Physics, University of Tasmania, GPO Box 252-80, \\ Hobart 7001, Tasmania, Australia \\ ${ }^{3}$ Antarctic Wildlife Research Unit, School of Zoology, University of Tasmania, GPO Box 252-05, Hobart 7001, \\ Tasmania, Australia
}

\begin{abstract}
This description of 905 scats from 4 locations in east Antarctica almost doubles the observations of Weddell seal diet reported to date. Regional, temporal and fine-scale spatial variation in diet was evaluated using both randomisation and parametric statistics. Even within the Vestfold Hills $\left(68^{\circ} 33^{\prime} \mathrm{S}, 78^{\circ} 15^{\prime} \mathrm{E}\right)$ there were several different ecotypes. In the southern fjords the diet was benthic fish and prawns, whereas in the northern area the diet was dominated numerically by Pleuragramma antarcticum - a species of pelagic schooling fish. Along the Mawson coast $\left(68^{\circ} 00^{\prime} \mathrm{S}\right.$, $63^{\circ} 00^{\prime}$ E) the diet was spatially homogeneous but varied over time. Squid Psychroteuthis glacialis was an important prey type for a short time in spring, and octopus was also abundant in the Mawson diet. As higher order predators, cephalopods represent another layer of complexity in the food web at Mawson. Both Vestfold Hills and Mawson seemed to be good foraging areas compared with Commonwealth Bay $\left(67^{\circ} 00^{\prime} \mathrm{S}, 142^{\circ} 30^{\prime} \mathrm{E}\right)$ and Larsemann Hills $\left(69^{\circ} 24^{\prime} \mathrm{S}, 76^{\circ} 13^{\prime} \mathrm{E}\right)$, where seals appeared to have eaten less during the summer haul-out period. This investigation described inshore diets using scats from coastal haul-out sites; it also showed that small crustaceae (mysids) were an important prey type, thus revealing the capacity for Weddell seals to join the krill-feeding communities north of the continental shelf. The variety in diet composition demonstrated both flexibility in the Weddell seals' foraging response and the range of different prey species available to Weddell seals over the Antarctic continental shelf and slope. In all but the most southerly area reported to date (McMurdo Sound), the seals take multiple prey species, which may minimise the coupling between Weddell seal population dynamics and the dynamics of their prey.
\end{abstract}

KEY WORDS: Diet - Variability - Weddell seal · Multivariate statistics · Antarctic · Chorismus · Trematomus $\cdot$ Pleuragramma $\cdot$ Psychroteuthis

\section{INTRODUCTION}

Investigation of the diets of seals and seabirds is essential for understanding their role in marine ecosystems. These high-level predators can integrate information about several layers of primary and secondary production and thus can be used for describing and monitoring spatial and temporal ecosystem dynamics. Weddell seals Leptonychotes weddellii are one of few high-level predators that forage in Antarctic coastal ecosystems. Their unique hole-breathing behaviour allows them to live under continuous sea-ice. Combined with the ability to dive to depths of 700 to $800 \mathrm{~m}$ (Castellini et al. 1992, Testa 1994), Weddell seals are the only air-breathing predator capable of foraging in both benthic and pelagic habitats throughout the icecovered oceans over the Antarctic continental shelf.

The diet of Weddell seals has been described at several locations around Antarctica (Fig. 1) and repeat descriptions for specific locations have been relatively 


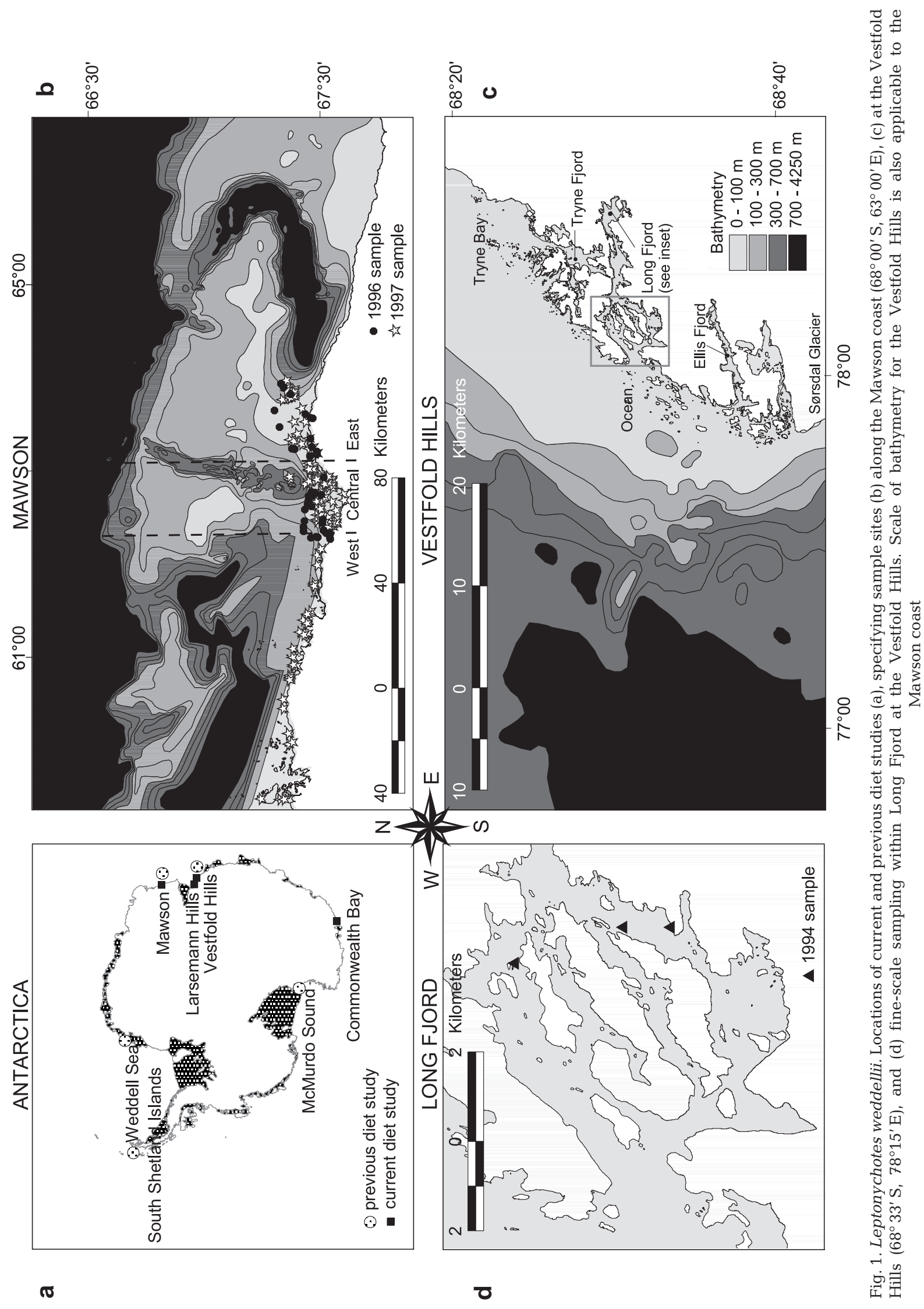


consistent. Two studies at the Vestfold Hills have revealed that benthic and pelagic fish, and prawns, comprise the diet at the Vestfold Hills (Green \& Burton 1987, Green et al. 1995). Pelagic fish are predominant in the diet in McMurdo Sound (Testa et al. 1985, Burns et al. 1998). Cephalopods are the main prey type at both South Shetland Islands and Mawson (Lipinski \& Woyciechowski 1981, Clarke \& McLeod 1982, Green \& Burton 1987, Casaux et al. 1997). Both benthic and pelagic fish are consumed over the continental slope in the Weddell Sea (Plötz 1986, Plötz et al. 1991). This marked regional variation in diet composition, and the huge area of ocean surrounding even coastal Antarctica, necessitates diet analysis from other locations to strengthen our understanding of Weddell seal foraging.

Antarctic waters have marked seasonal fluctuations in light and productivity, both factors being linked and attenuated by summer melt of snow and sea-ice (Eastman 1993). In addition, climate and oceanography cycles around the Southern Ocean have a 4 to $5 \mathrm{yr}$ periodicity (White \& Peterson 1996). However, seasonal and inter-annual variation has not yet been characterised for Weddell seal diet. The variation in diet described by Plötz et al. (1991) could have had both seasonal and inter-annual elements because seasons were sampled in different years and only one season was replicated. Variation in diet described by Green \& Burton (1987) over 13 mo and in 2 areas did not characterise the changes because seasons were not sampled repeatedly and the scale of spatial variation was not considered. Green et al. (1995) compared scats from several years collected over similar dates but from unspecified locations, and thus, even this inter-annual comparison could have been confounded by fine-scale spatial variation in the diet.

This study evaluates fine-scale spatial and seasonal variation in the Weddell seal diet, using scats collected in the spring and summer at the Vestfold Hills, and winter and spring in $2 \mathrm{yr}$ at Mawson. Diets were described for another 2 locations in summer, and regional comparisons were standardised by time of year. Most of our collections are replicated, although not necessarily from the same sites and seasons in each year and at every location. The scats were collected from the top of the sea-ice. Research on Antarctic seaice is difficult in all seasons due to the changing extent of ice cover and remoteness. This analysis of 905 scats from 4 locations in east Antarctica almost doubles the description of the Weddell seal diet to date.

\section{MATERIALS AND METHODS}

Some species of seal eliminate prey hard parts by both defaecation and regurgitation (Pierce \& Boyle
1991). However, whilst collecting over 900 scats we sighted only 2 regurgitates. These contained undigested fish, squid and prawns apparently eliminated unselectively and possibly in response to overconsumption. Given these observations, it was assumed that Weddell seals generally eliminate all prey remains by defaecation and thus our study was based solely on faeces (scats). Only whole and relatively fresh scats were collected. Care was taken to chip each scat off the ice without damaging it, and some ice was collected with the faeces. We did not remove the ice to measure the mass of each scat. As in other studies (e.g. Green \& Burton 1987, Burns et al. 1998), a single scat of variable mass was the sampling unit. Samples were frozen until analysis.

New method for processing faecal samples. A new method of washing scats in a conventional clothes washer was developed based on a reference in Pierce \& Boyle (1991), where terrestrial scats were washed in nylon stockings. The method was developed after finding that the open system elutriator of Bigg \& Olesiuk (1990) was not suitable for Weddell seal scats because the already established method relied on a difference in the density of diagnostic remains compared to flocculent material. This difference could not be used in our study because the crustacean exoskeletons would have been washed away.

Bags of 2 sizes were constructed from scientific-grade plankton net. The smaller bag had a mesh diameter of $1 \mathrm{~mm}$ and the larger bag $0.25 \mathrm{~mm}$. The bags were closed by Velcro ${ }^{\mathrm{TM}}$ and U-shaped so that they could be inverted and cleaned. Each scat was washed while nested in both bags. It took about $10 \mathrm{~min}$ for the flocculent material to be removed. It was possible using this technique to wash several scats separately but at the same time. Gentle agitation in water removed the flocculent without damaging even the most delicate remains such as crustacean exoskeletons. The scats were washed outside the laboratory and the faecal odour was greatly reduced by the time the remaining hard parts were brought inside for sorting. The bags for each scat were washed in a $20 \mathrm{l}$ bowl, the contents of the bowl drained through a $0.25 \mathrm{~mm}$ mesh sieve, and the contents of the sieve transferred to a sorting dish. We tested retention capabilities of this system by seeding the bags with $1 \mathrm{~mm}, 0.7 \mathrm{~mm}$, and $300 \mu \mathrm{m}$ glass beads, and processing scats as usual. Approximately $95 \%$ of the medium and large-size beads were retrieved from the first wash. This indicated that prey remains greater than $0.7 \mathrm{~mm}$ were being recovered, and that there was minimal carry-over of remains within the mesh bags. As a second check we placed a $100 \mu \mathrm{m}$ mesh sieve at the outfall and confirmed that all sagittal otoliths, cephalopod beaks and whole crustacean exoskeletons had been retained in the bags. 
Identification and quantification of prey. Fish taxa were identified and quantified by sagittal otoliths with reference to Williams \& McEldowney (1990). The number of fish per scat was quantified as the maximum number of either left or right otoliths for each species. Lengths of uneroded otoliths were measured by digital image analysis using a microscope and image analysis software. Standard length and body mass (BM) of fish were estimated from otolith lengths using speciesspecific allometric equations from Williams \& McEldowney (1990). Trematomus type otoliths (Williams \& McEldowney 1990) were distinct from Pleuragramma antarcticum otoliths, which were distinct from channichthyd otoliths. Trematomus type otoliths too eroded to identify were categorised as eroded benthic fish, except for the very small Trematomus type otoliths that were categorised as juvenile fish. Channichthyid, eroded and juvenile fish otoliths had no distinct features by which to make species-specific identifications. To estimate mass, channichthyid otoliths were measured and assumed to be Chaenodraco wilsoni (a medium size channichthyid and a common constituent of the diet of predators in Prydz Bay, Williams \& McEldowney 1990). Both juvenile fishes (estimated standard length $7 \mathrm{~cm}$ ) and eroded otoliths (estimated average length of uneroded $T$. bernacchii otoliths) were assumed to be $T$. bernacchii (a common species of benthic fish in inshore environments; Eastman 1993).

Cephalopod taxa were identified and quantified by lower beaks with reference to Clarke (1986), Daly \& Rodhouse (1994), Allcock \& Piertney (2002) and a collection vouched for by M. Clarke located at the Australian Antarctic Division, Tasmania. Squid lower-beak rostral lengths and octopus lower-beak hood lengths were measured using digital vernier callipers. The mass of Psychroteuthis glacialis was estimated using an allometric equation from Gröger et al. (2000). Except for Pareledone polymorpha (Daly \& Rodhouse 1994, Allcock \& Piertney 2002), there were no distinguishing features by which to group the octopus lower beaks into different taxa. Initially, it was assumed that all octopus lower beaks not identified as P. polymorpha were actually $P$. turquetti, and mass was estimated using figures in Daly \& Rodhouse (1994). However, the resulting estimate of $250 \mathrm{~g}$ was large compared to observations from Weddell seal regurgitates (S. Lake unpubl. data), and also the masses estimated by Casaux et al. (1997) for octopus in the Weddell seal diet and the relatively small mantle lengths described by Allcock et al. (2001). Considering this, we made a general estimate for octopus body mass at $100 \mathrm{~g}$.

Prawn taxa were identified and quantified by number using their carapaces with reference to Kirkwood (1983). Prior to this study there were no published allometric equations for estimating the body mass of these

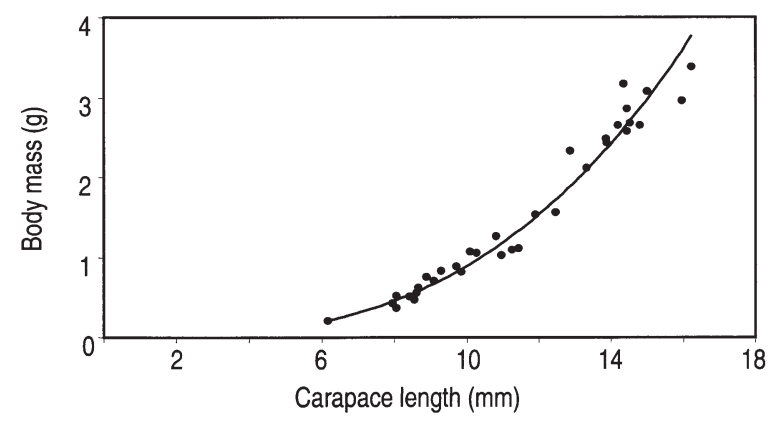

Fig. 2. Chorismus antarcticus. Regression equation relating carapace length (CL) to body mass (BM) for 35 prawns caught in traps at the entrance to Ellis Fjord, Vestfold Hills

prawns from carapace length (CL). To address that problem, bait traps were set in Ellis Fjord (Vestfold Hills) and CL and BM were measured for each of the 35 Chorismus antarcticus caught in the traps. CL ranged from 6 to $16 \mathrm{~mm}$. The best-fit regression formula was an exponential function: $\mathrm{BM}=$ $0.000943(\mathrm{CL})^{2.976}, R^{2}=0.976$ (Fig. 2). We used the same allometric equation to estimate the BM of Notocrangon antarcticus because the 2 prawn species have a similar morphology (Kirkwood 1983). The BM of mysids was assumed to be equivalent to the wet mass of mysid exoskeletons in processed scats. Mysid exoskeletons were mainly intact and, flooded with water, the mass of exoskeletons would have been similar to the undigested mass of these small-bodied crustaceans.

Study areas and sampling design. At the Vestfold Hills $\left(68^{\circ} 33^{\prime} \mathrm{S}, 78^{\circ} 15^{\prime} \mathrm{E}\right.$, Fig. 1), the distribution of Weddell seals changed from pupping sites in spring to moulting sites in summer (Green et al. 1995). Long Fjord was the main pupping area, where approximately 100 pups suckled from October to December. The Tryne area was also used for pupping ( 40 pups per annum); but mainly for moulting as several hundred seals aggregated in this area from January to March each year. Pupping aggregations included mother-pup pairs and non-pupping seals of both sexes. Overall, $56 \%$ of the Vestfold Hills spring sample was from pupping colonies and the remainder was from nonpupping sites throughout the fast-ice areas.

In spring at the Vestfold Hills, over-snow vehicles were used for transport and the main constraint to sampling was paucity of scats in the Tryne area. In summer, after most of the sea-ice had melted, helicopters were used for transport and this was possible in 1995 and 1996 only. At Mawson $\left(68^{\circ} 00^{\prime} \mathrm{S}, 63^{\circ} 00^{\prime} \mathrm{E}\right.$, Fig. 2), helicopters were not available. A regular sampling regime was maintained throughout winter (April to September) and spring in both 1996 and 1997 but not in summer of either year. One third of the Mawson spring sample was from pupping colonies. At the Larsmann Hills $\left(69^{\circ} 24^{\prime} \mathrm{S}, 76^{\circ} 13^{\prime}\right.$ E, Fig. 1), a sample was 
obtained from Thala Fjord in January 1996. At Commonwealth Bay $\left(67^{\circ} 00^{\prime} \mathrm{S}, 142^{\circ} 30^{\prime} \mathrm{E}\right.$, Fig. 1), a sample was obtained from Boat Harbour in January 1997.

Data analysis. Frequency of occurrence described the rate at which prey types were targeted (Table 1). Number of prey remains conveyed additional information about the relative proportions of prey in the diet. Estimates of mass took into account the number and also size of prey to describe species' contributions to the diet. However, the estimate of octopus mass was imprecise and this would have affected the relative mass of other prey types. To minimise this inaccuracy, we based our statistical analyses on numerical data and simply interpreted the test results with regard to body mass of prey (Table 2).

We compared diet composition by randomisation (Manly 1997) and parametric methods (Johnson \& Field 1993). Both tests were performed in S-Plus (Insightful Applications) using matrices of number of each prey species per scat. Randomisation tests bound the columns (prey species) while randomising the rows (sample labels). Two-way randomisation tests were conducted as separate 1-way analyses, where one factor was held constant (e.g. year) while the other factor (e.g. location) was randomised, and vice versa. Under the null hypothesis, the randomised factor was not significant in determining the diet. The steps to randomisation were (a) calculating the $F$-statistic for observed data, (b) randomising the labels 5000 times to calculate the distribution of the $F$-statistic under the null hypothesis, and (c) comparing the $F$-statistic of the observed difference with the distribution of $F$ under the null hypothesis. If the null hypothesis was true then the observed value of $F$ was within the distribution of $95 \%$ of the Fs calculated from random allocation. This approach made few assumptions about the data (Manly 1997) but did not test for interaction effects.

Parametric tests were done by MANOVA (multivariate analysis of variance) using Type-1 sums of squares. The assumptions of MANOVA were multi-normality of error terms and homogeneity of group co-variances (Johnson \& Field 1993). In this case, the data were not

Table 1. Leptonychotes weddellii. Diet at Commonwealth Bay (CB), Larsemann Hills (LH), Mawson (M) and the Vestfold Hills $(\mathrm{VH})$ described by frequency of occurrence $(\%)$, mean number of prey per scat, mean mass of prey per scat and percentage of total estimated mass of prey in the diet $\left(<0.5={ }^{\prime} 0^{\prime}\right.$, not detected $\left.={ }^{\prime}-{ }^{\prime}\right)$. Samples were from summer 1996 at CB $(86 \mathrm{scats})$, summer 1997 at LH (29 scats), winter and spring 1996-97 at M (201 scats) and spring and summer 1992-96 at VH (585 scats)

\begin{tabular}{|c|c|c|c|c|c|c|c|c|c|c|c|c|c|c|c|c|}
\hline & \multicolumn{4}{|c|}{$\begin{array}{l}\text { Frequency of } \\
\text { occurrence (\%) }\end{array}$} & \multicolumn{4}{|c|}{$\begin{array}{c}\text { Mean no. prey } \\
\text { per scat }\end{array}$} & \multicolumn{4}{|c|}{$\begin{array}{l}\text { Mean mass prey } \\
\text { per scat }(\mathrm{g})\end{array}$} & \multicolumn{4}{|c|}{$\begin{array}{l}\text { Proportion total } \\
\text { mass }(\%)\end{array}$} \\
\hline & $\mathrm{CB}$ & LH & $\mathrm{M}$ & $\mathrm{VH}$ & $\mathrm{CB}$ & $\mathrm{LH}$ & $\mathrm{M}$ & $\mathrm{VH}$ & $\mathrm{CB}$ & LH & M & $\mathrm{VH}$ & $\mathrm{CB}$ & LH & $\mathrm{M}$ & $\mathrm{VH}$ \\
\hline Fish (total) & 13 & 39 & 60 & 39 & 2 & 4 & 13 & 6 & 64 & 53 & 157 & 114 & 60 & 75 & 17 & 68 \\
\hline Pleuragramma antarcticum & 6 & 27 & 41 & 8 & 1 & 2 & 10 & 3 & 25 & 38 & 62 & 11 & 23 & 54 & 7 & 7 \\
\hline Juvenile fish & - & 15 & 18 & 7 & - & 1 & 1 & 1 & - & 5 & 6 & 6 & - & 7 & 1 & 4 \\
\hline Eroded benthic otoliths & 7 & 9 & 11 & 14 & 0 & 0 & 0 & 1 & 18 & 8 & 24 & 53 & 16 & 11 & 3 & 32 \\
\hline Aethotaxis mitopteryx & - & - & 0 & - & - & - & 0 & - & - & - & 1 & - & - & - & 0 & - \\
\hline Channichthyidae & 1 & 3 & 10 & 2 & 0 & 0 & 0 & 0 & 0 & 1 & 15 & 2 & 0 & 2 & 2 & 1 \\
\hline Dissostichus mawsoni & 1 & - & - & - & 0 & - & - & - & 0 & - & - & - & 0 & - & - & - \\
\hline Lepidonotothen kempi & - & - & 1 & 2 & - & - & 0 & 0 & - & - & 0 & 1 & - & - & 0 & 1 \\
\hline Notothenia coriiceps & - & - & 0 & 0 & - & - & 0 & 0 & - & - & 0 & 0 & - & - & 0 & 0 \\
\hline Pagothenia borchgrevinki & 1 & - & 1 & 4 & 0 & - & 0 & 0 & 0 & - & 1 & 4 & 0 & - & 0 & 2 \\
\hline Trematomus bernacchii & 1 & - & 2 & 13 & 0 & - & 0 & 1 & 8 & - & 3 & 16 & 8 & - & 0 & 9 \\
\hline T. eulepidotus & - & - & 2 & 0 & - & - & 0 & 0 & - & - & 3 & 0 & - & - & 0 & 0 \\
\hline T. hansoni & - & 3 & - & 0 & - & 0 & - & 0 & - & 1 & - & 0 & - & 1 & - & 0 \\
\hline T. lepidorhinus & - & - & 3 & 1 & - & - & 0 & 0 & - & - & 8 & 1 & - & - & 1 & 1 \\
\hline T. loenbergi & - & - & 1 & 1 & - & - & 0 & 0 & - & - & 1 & 3 & - & - & 0 & 2 \\
\hline T. newnesi & 1 & - & 4 & 2 & 0 & - & 0 & 0 & 12 & - & 29 & 8 & 11 & - & 3 & 5 \\
\hline T. pennelii & 1 & - & 2 & 3 & 0 & - & 0 & 0 & 0 & - & 5 & 3 & 0 & - & 1 & 2 \\
\hline T. scotti & 2 & 1 & 8 & 0 & - & 0 & 0 & 1 & - & 0 & 6 & 0 & - & 0 & 4 & \\
\hline Cephalopods (total) & 17 & 6 & 56 & 9 & 0 & 0 & 7 & 0 & 38 & 10 & 756 & 31 & 36 & 14 & 82 & 18 \\
\hline Pareledone polymorpha & - & - & 2 & - & - & - & 0 & - & - & - & 7 & - & - & - & 1 & - \\
\hline Pareledone spp-. & 17 & 3 & 41 & 8 & 0 & 0 & 3 & 0 & 38 & 6 & 343 & 27 & 36 & 8 & 37 & 16 \\
\hline Psychroteuthis glacialis & - & 3 & 36 & 1 & - & 0 & 3 & 0 & 0 & 4 & 406 & 4 & 5 & 44 & 2 & \\
\hline Crustaceans (total) & 24 & 6 & 18 & 35 & 2 & 0 & 1 & 8 & 4 & 1 & 1 & 57 & 4 & 1 & 0 & 34 \\
\hline Chorismus antarcticus & 24 & 3 & 15 & 33 & 2 & 0 & 0 & 6 & 4 & 1 & 1 & 14 & 4 & 1 & 0 & 8 \\
\hline Notocrangon antarcticus & - & 3 & 5 & 9 & - & 0 & 0 & 2 & - & 0 & 1 & 6 & - & 0 & 0 & 3 \\
\hline Mysid & 1 & 15 & 21 & 6 & - & - & - & - & 1 & 8 & 11 & 3 & 0 & 11 & 1 & 2 \\
\hline Total & 63 & 84 & 217 & 122 & 4 & 4 & 20 & 15 & 107 & 71 & 925 & 167 & 100 & 100 & 100 & 100 \\
\hline
\end{tabular}


Table 2. Leptonychotes weddellii. Prey size (mean, SD and median in brackets), estimated from the lengths of the undigested diagnostic remains recovered in 905 scats. Data are standard lengths for fish, mantle lengths for cephalopods and total lengths for prawns. Allometric equations were from Williams \& McEldowney (1990) or as specified. When no allometric equation is available, data are not presented

\begin{tabular}{|c|c|c|c|}
\hline Prey type (n) & Length of prey remains (mm) & Length of prey (mm) & Mass of prey $(\mathrm{g})$ \\
\hline \multicolumn{4}{|l|}{ Fish } \\
\hline Aethotaxis mitopteryx (2) & 0.1 & & 80.0 \\
\hline Channichthyidae (26) & $1.7 \pm 0.1(1.7)$ & $163.7 \pm 4.2(164.4)$ & $42.0 \pm 3.8(40.0)$ \\
\hline Lepidonotothen kempi (15) & $3.5 \pm 0.9(3.5)$ & $112.9 \pm 54.3(110.6)$ & $36.7 \pm 46.5(18.8)$ \\
\hline Notothenia coriiceps (3) & $2.8 \pm 0.5(2.5)$ & $211.5 \pm 37.1(190.8)$ & $216.2 \pm 139.6(154.5)$ \\
\hline Pagothenia borchgrevinki (14) & $2.4 \pm 0.5(2.4)$ & $146.6 \pm 44.8(147.2)$ & $66.3 \pm 55.1(51.8)$ \\
\hline Pleuragramma antarcticum (1972) & $1.0 \pm 0.2(1.0)$ & $93.1 \pm 17.4(91.1)$ & $6.1 \pm 5.2(5.1)$ \\
\hline Trematomis hansoni (2) & $2.3 \pm 0.6(2.3)$ & $100.4 \pm 32.5(100.4)$ & $15.6 \pm 16.8(15.6)$ \\
\hline T. bernacchii (263) & $2.9 \pm 0.7(2.9)$ & $115.0 \pm 32.0(113.4)$ & $26.2 \pm 24.9(19.8)$ \\
\hline T. eulepidotus (2) & $3.9 \pm 0.2(3.9)$ & $201.3 \pm 10.4(201.3)$ & $162.3 \pm 45.8(162.3)$ \\
\hline T. lepidorhinus (11) & $4.2 \pm 0.8(4.1)$ & $195.9 \pm 35.7(191.6)$ & $147.4 \pm 86.2(122.5)$ \\
\hline T. newnesi (50) & $2.4 \pm 0.4(2.4)$ & $178.6 \pm 20.8(178.7)$ & $96.9 \pm 34.4(93.0)$ \\
\hline T. penneli (65) & $3.5 \pm 0.6(3.4)$ & $113.6 \pm 23.8(110.8)$ & $30.5 \pm 21.1(24.3)$ \\
\hline T. scotti (50) & $3.4 \pm 1.0(3.5)$ & $86.4 \pm 21.7(88.3)$ & $11.6 \pm 9.4(9.8)$ \\
\hline \multicolumn{4}{|l|}{ Cephalopods } \\
\hline Pareledone polymorpha (7) & $5.4 \pm 1.1(5.1)$ & & \\
\hline Pareledone spp. (396) & $8.7 \pm 3.1(8.4)$ & & \\
\hline Psychroteuthis glacialis (248) & $3.4 \pm 2.0(2.3)$ & $93.6 \pm 141.8(9.8)^{\mathrm{b}}$ & $123.0 \pm 83.3(76.4)^{b}$ \\
\hline \multicolumn{4}{|l|}{ Crustaceans } \\
\hline Chorismus antarcticus (2072) & $13.9 \pm 1.7(13.8)$ & $74.2 \pm 8.3(73.8)$ & $2.4 \pm 0.6(2.4)^{\mathrm{a}}$ \\
\hline Notocrangon antarcticus (442) & $14.3 \pm 2.4(14.1)$ & $71.2 \pm 10.6(70.2)$ & $2.6 \pm 0.8(2.5)^{\mathrm{a}}$ \\
\hline
\end{tabular}

homoscedastic or normally distributed for any of the prey types, and could not be transformed as such because of the large number of zeros. Although it was inappropriate to ignore the assumptions, it was equally improper to reject the test as invalid since many statistics are robust to violations of their theoretical requirements (Johnson \& Field 1993). We found that the randomisation tests and MANOVA gave similar results, although randomisation procedures yielded more conservative significance levels. The results from randomisation are quoted unless the results of the 2 tests differed, in which case both results are given. Univari-

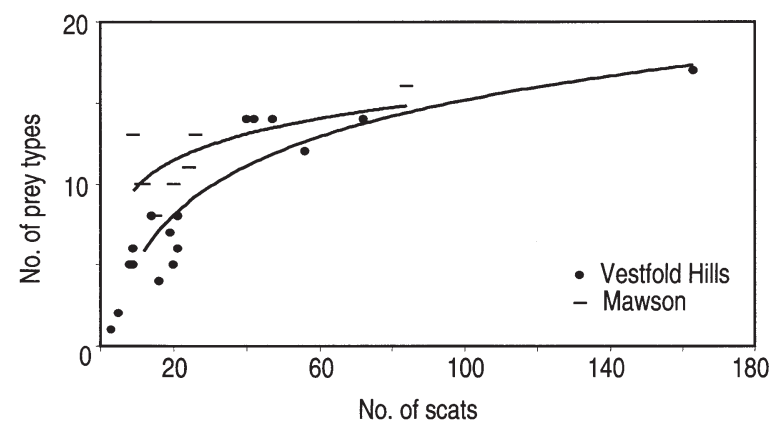

Fig. 3. Leptonychotes weddellii. Number of prey types described in the diet relative to the number of scats processed, for samples from the Vestfold Hills and Mawson ate versions of the same tests (with $\alpha$-levels of $p=0.05$ ) were used to interpret the results of multivariate tests.

Prior to analysis, the data were reduced according to a criterion of percentage dominance (Field et al. 1982). By this method, we retained all species with frequency of occurrence greater than $10 \%$ in at least one sample collection. Four species of benthic fish did not meet the criterion: Pagothenia hansoni, Trematomus centronotus, Notothenia kempi and N. neglecta (Table 1). These species were not abundant in any of the samples.

\section{RESULTS}

The number of species in the diet was related to number of scats in the sample (Fig. 3): About 10 prey types were described from 15 to 25 scats whereas about 14 prey types were described from 40 to 60 scats. Sample sizes for different areas, seasons and years varied from 8 to 163 scats, and this was a potential source of variation in the diet descriptions. However, the statistical techniques compared number of individuals per species per scat rather than the average number of individuals per species per sample. Furthermore, rare species were eliminated prior to analysis to avoid coincidental co-occurrence of rare species dominating the 
results. In these ways, variation in diet due to irregular sample sizes was minimised; but this source of variation should still be considered with regard to number of prey species described in the diets, and the reliability of quantitative estimates for prey species that occurred infrequently in the samples (Fig. 3).

\section{Spring diet at the Vestfold Hills}

The finest scale examined in this study was within Long Fjord in 1994 (Fig. 1). We compared scats from 3 colonies in October (19, 19 and 31 scats per colony) and December (17, 18 and 31 scats per colony). Both randomisation and MANOVA indicated that variation between pupping colonies was not significant $\left(F_{4,122}=\right.$ $0.70, \mathrm{p}=0.16)$, and neither was variation over time $\left(F_{3,121}=0.77, \mathrm{p}=0.18\right)$.

On a broader scale, the Vestfold Hills' spring diet was described from 423 scats collected between 1992 and 1995 . The majority ( $70 \%$ ) of the spring collection was from Long Fjord (Fig. 1) (47, 42, 163 and 40 scats per year, from 1992 to 1995 respectively). The Tryne area was sampled irregularly due to paucity of scats (8, 30,0 and 8 scats). The rest of the spring collection was from oceanic areas where non-pupping seals hauled out $(0,20,56$ and 9 scats). Overall, $65 \%$ of scats had evidence of prey; on average there was evidence of 12.7 prey per scat, and 17 different prey types were identified.

Within the spring diet (Fig. 4), both randomisation and MANOVA showed significant effects for location $\left(F_{6,419}=0.72, \mathrm{p}=0.04\right)$ and for year $\left(F_{7,420}=0.72, \mathrm{p}=\right.$ $0.02)$. Univariate randomisations suggested that the location effect was due to Trematomus bernacchii occurring exclusively in Long Fjord samples. Prawns Chorismus antarcticus and Notocrangon antarcticus were also relatively abundant in the Long Fjord samples. Pleuragramma antarcticum occurred mainly in samples from the Tryne area. Inter-annual differences were attributed to prawns and juvenile fish; however, both these prey types were abundant yet small, thus dominating numerical tests more than diet composition (Table 2).

\section{Summer diet at the Vestfold Hills}

The summer diet (Fig. 5) at the Vestfold Hills was described from 163 scats collected in 1995 and 1996. Most of the summer collection was from the Tryne area (35 and 86 scats per year). There were also 20 scats from Ellis Fjord in 1995, and 21 scats from Long Fjord in 1996. Overall, $53 \%$ of scats contained evidence of prey; on average there was evidence of 8.2 prey per scat, and 14 different prey types were identified. This was slightly less prey than quantified at the Vestfold Hills in spring.

Both randomisation and MANOVA indicated that location was a significant determinant of the summer

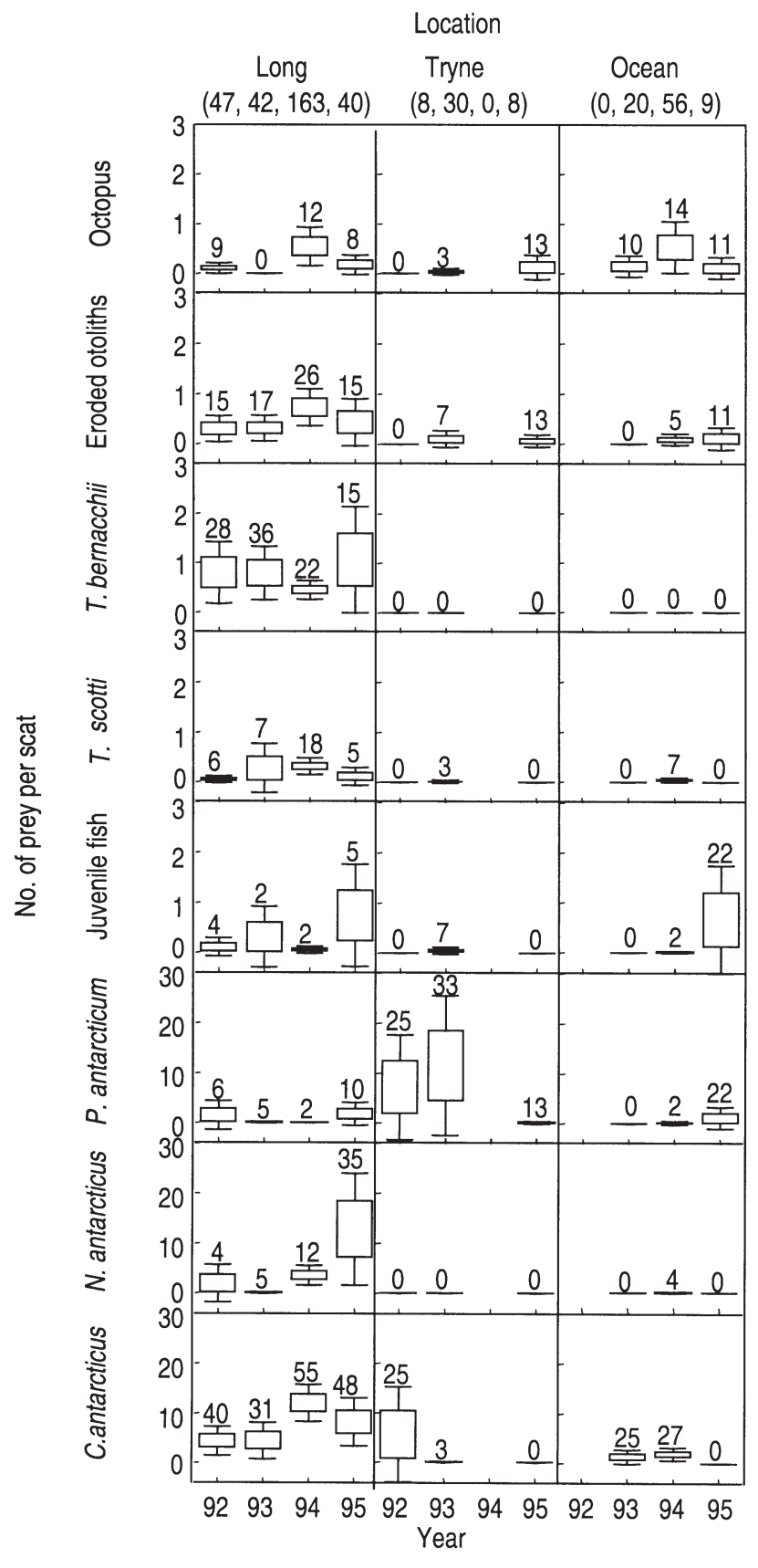

Fig. 4. Leptonychotes weddellii. Temporal and spatial variation within the spring diet at the Vestfold Hills (Long Fjord, Tryne area and Ocean). Numerical abundance of each prey type is shown by a box of $1 \mathrm{SE}$ around the mean, with whiskers at $95 \%$ CIs. Frequency of occurrence (\%) is given above each plot, and number of scats per sample is listed in brackets after location 
diet at the Vestfold Hills $\left(F_{2,160}=0.68, \mathrm{p}<0.00\right.$, Fig. 5). As in spring, both prawn species were relatively abundant in the Long Fjord sample. In summer, Chorismus antarcticus was relatively abundant in the Ellis Fjord sample too. Inter-annual variation was not significant

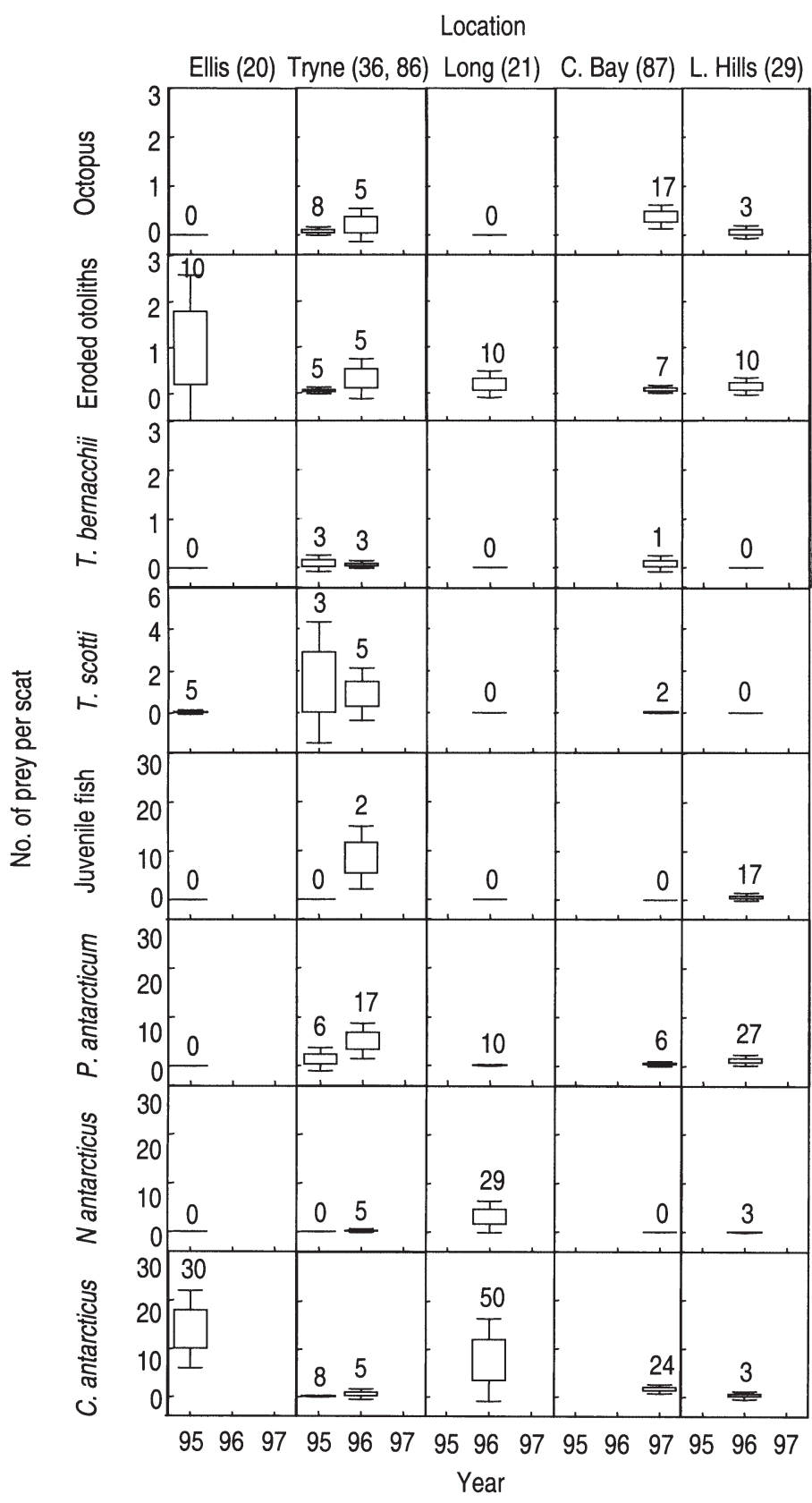

Fig. 5. Leptonychotes weddellii. Temporal and spatial variation within the summer diet at the Vestfold Hills (Ellis Fjord, Tryne area and Long Fjord), and also at Commonwealth Bay (C. Bay) and Larsemann Hills (L. Hills). Numerical abundance of each prey type is shown by a box of $1 \mathrm{SE}$ around the mean, with whiskers at $95 \%$ CIs. Frequency of occurrence (\%) is given above each plot, and number of scats per sample is listed in brackets after location in summer at the Vestfold Hills $\left(F_{1,160}=0.92, \mathrm{p}=0.44\right)$. However this may be an overly conservative result since the data was limited to 2 yr and the Tryne area only. Similarly, our tests indicated that seasonal variation was not significant in the Vestfold Hills diet $\left(F_{1,167}=0.89, \mathrm{p}=0.06\right)$. However, this comparison was limited to the Tryne area only, where 3 yr were sampled in spring and 2 in summer. With this sample collection, we could not evaluate seasonal variation in the diet of seals in a satisfactory way.

\section{Winter and spring diets at Mawson}

Spring diet at Mawson was described from 58 scats, including 9 scats from the central coast in 1996, and 26, 11 and 12 scats from the east, west and central coasts in 1997 (Fig. 1). In spring, 90\% of scats contained prey remains; on average there was evidence of 20.4 prey per scat, and 14 prey types were identified. For winter, the diet at Mawson was described from 143 scats, including 15 scats from the central coast in 1996, and 24, 21 and 84 scats from east, west and central areas in 1997. In winter, $73 \%$ of scats contained prey remains; on average there was evidence of 10.6 prey per scat, and 15 taxa were identified. This was more prey by number and mass than evidenced in the diet at the Vestfold Hills (Table 1).

The difference between winter and spring diets at Mawson was significant by both randomisation and MANOVA $\left(F_{1,200}=0.82, \mathrm{p}<0.00\right)$. It was attributed mainly to the squid Psychroteuthis glacialis and

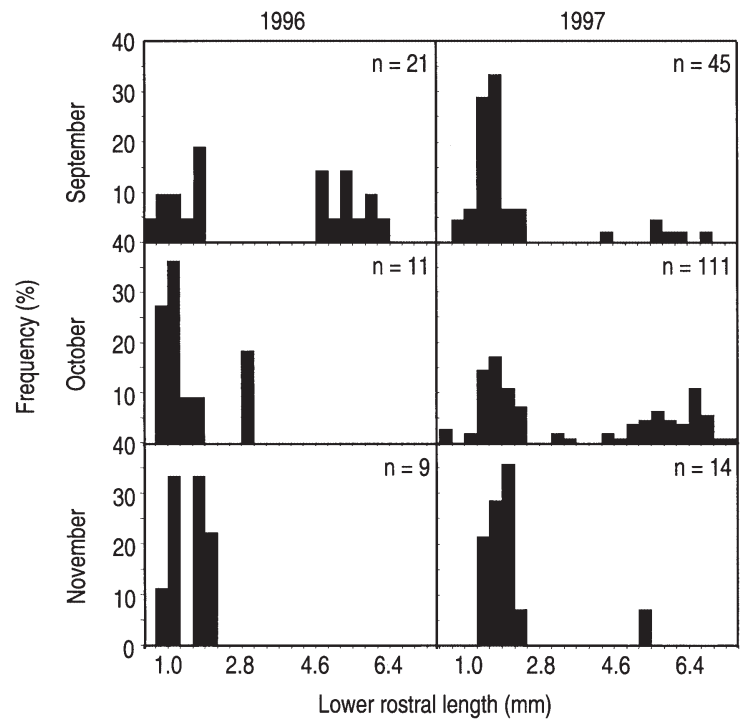

Fig. 6. Psychroteuthis glacialis. Length frequency distribution evidenced by rostral lengths of lower beaks in scats from Mawson, September to November of 1996 and 1997 
Trematomus bernacchii being more abundant in spring. Overall, P. glacialis was the dominant prey type (44\% mass, Table 1). T. bernacchii was relatively unimportant in the Mawson diet (<1\% mass). $P$. glacialis was abundant in scats from September to November in both years, with a bimodal distribution of size-classes (Fig. 6). The larger size-class disappeared from the diet in October 1996 and in November 1997. With regard to octopus, apart from Pareledone polymorpha the octopus beaks in the Mawson diet had a normal length-frequency distribution, suggesting that they represented a single species. Inter-annual variation in the Mawson diet was significant by MANOVA $\left(F_{1,195}=2.61, \mathrm{p}>0.00\right)$ but not by randomisation $\left(F_{3,198}=0.57, \mathrm{p}=0.08\right)$. This ambiguous result could reflect the different sample sizes used to represent 1996 compared to 1997. The effect of location was not significant in Mawson diet, either by randomisation or MANOVA $\left(F_{4,199}=0.56, \mathrm{p}<0.11\right)$.

\section{Regional comparisons}

The Vestfold Hills and Mawson diets, compared in spring, were significantly different by both randomisation and MANOVA tests $\left(F_{1,480}=0.65, \mathrm{p}<0.00\right)$. There were significantly more channichthyds, Pleuragramma antarcticum, Trematomus newnesi, squid and octopus in the Mawson diet, and more T. bernacchii and Chorismus antarcticus in the Vestfold Hills diet. At Mawson, a large proportion of scats contained evidence of prey remains and multiple prey types occurred commonly in the same scat (Fig. 7). Overall, more prey was represented in scats from Mawson (Table 1).

Summer diets were described for Commonwealth Bay in 1997 (87 scats) and Larsemann Hills in 1996 (29 scats), as well as the Vestfold Hills in 1995 and 1996 (Fig. 5). Paucity of prey distinguished the Commonwealth Bay and Larsemann Hills collections (2.8 and 2.4 prey per scat respectively) from the Vestfold Hills collection (8.2 prey per scat). While randomisation tests showed that variation between these collections was not significant $\left(F_{2,281}=0.89, \mathrm{p}<0.16\right)$, MANOVA showed a significant effect $\left(F_{3,276}=0.65, \mathrm{p}<0.00\right)$

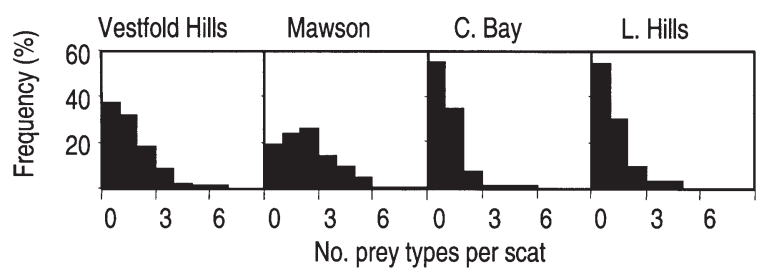

Fig. 7. Leptonychotes weddellii. Number of prey types recovered per scat, where numbers varied from zero identifiable prey to 8 different prey types occurring in the same scat due to prawns being more abundant in the Vestfold Hills and Commonwealth Bay diets.

\section{DISCUSSION}

\section{Caveats on the data}

Feeding trials have shown that using scats to estimate prey composition yields biased results because prey remains are differentially digested (Pierce \& Boyle 1991, Lake 1997, Staniland 2002). Fish otoliths are more susceptible to digestion than cephalopod beaks and prawn exoskeletons. Thus abundance and perhaps size of fish is underestimated relative to other prey types. Severity of digestion varies according to predator species, prey species, meal size, prey size and predator behaviour (Bowen 2000). Weddell seal digestion appears to be relatively severe, perhaps due to ingestion of substrate similar to other benthic foragers, such as Australian sea lions Neophoca cinerea (Gales \& Cheal 1992). We found sand in $44 \%$ of scats, and stones in $14 \%$ of scats, which probably contributed to mechanical digestion. In this case, the substrate must have come from the gut because the scats were collected from ice. Feeding trials specific to Weddell seals have not been conducted but severity of digestion is evident from the low numbers of otoliths recovered from scats, specifically no otoliths at all (Testa et al. 1985), 0.81 otoliths per scat (Green \& Burton 1987) and 0.95 otoliths per scat (Burns et al. 1998). However, conclusions about changes in diet are still valid, assuming that the biases remain constant. This assumption may be incorrect when the severity of digestion increases due to small meal sizes and thus reduced passage rates during the moulting and pupping haul-out periods (Marcus et al. 1998). This is discussed with regard to differences in the overall abundance of prey evident in the samples.

Other potential biases include non-representative sample collections, consumption of prey without hard parts, and statistical power in detecting variability. Scats represent approximately $1 \mathrm{~d}$ of feeding (Bowen 2000) and we collected all of our scats from coastal areas so the diet descriptions are likely to be biased towards coastal prey species. Larger fish, such as channichthyids or Dissostichus mawsoni, were not evident in the diet but they may have been consumed and the heads not eaten (Pierce \& Boyle 1991). Finally, the power of some comparisons was limited. For example, the seasonal comparison at the Vestfold Hills was limited to the Tryne area, with 35 and 86 scats per year in summer compared with 8, 30 and 8 scats per year in spring. Lack of significant differences may have reflected small sample sizes and thus statistical power, 
rather than lack of change in the diet. This is in addition to 8 scats being a less than adequate replicate (Fig. 3).

Our study described the diet at the Vestfold Hills and Mawson as did Green \& Burton (1987). The earlier report differed mainly with regard to Trematomus scotti. Despite T. scotti being a common fish species with very distinctive otoliths, ours is the first report to identify T. scotti in the diet of any Antarctic predator (Williams \& McEldowney 1990). By retrieving otoliths from archives and checking identifications we found that Green \& Burton (1987) referred to T. scotti as Nototheniidae sp. 1, and T. newnesi as Nototheniidae sp. 2. Thus our findings were consistent with the previous report.

\section{Vestfold Hills}

Spatial variation in the diet of Weddell seals at the Vestfold Hills seemed to reflect different marine ecotypes within the fjords and bays, consistent with the findings of Dhargalkar et al. (1988), who attributed distribution of macro-algae species to different degrees of exposure to ocean currents. Within each ecotype, the seals' diet was relatively consistent (Figs. 4 \& 5). In Long and Ellis Fjords the diet contained prawns in quantities greater than in other regions of Antarctica (Plötz et al. 1991, Burns et al. 1998), yet this was consistent with the previous report for the Vestfold Hills (Green \& Burton 1987). Benthic fish, particularly Trematomus bernacchii, were also relatively abundant in Long Fjord. High levels of secondary biomass have been described in these fjords due to complex bathymetry and active tidal regimes, resulting in areas of rapid water flow and thus enhanced plankton 'pass by' flux (Kirkwood \& Burton 1988, Arntz \& Gorny 1991). Rapid water flow sustains tubeworm reefs that are substrate for populations of benthic prawns. Both prey availability and the seals' functional response (Bowen et al. 2002) determine diet composition. Weddell seals in the southern fjords of the Vestfold Hills seem accustomed to foraging on small benthic prey.

Localised prey resources could result in seals choosing sequential foraging locations according to prey availability. After the seals deplete benthic prey in Long Fjord in spring, they could harvest pelagic prey in the Tryne area in summer. The diet in the Tryne area was characterised by the pelagic fish Pleuragramma antarcticum, which feed on krill, which in turn feed on algae that bloom in summer as the ice melts (Plötz et al. 2001). The Tryne area is on the northern side of the Vestfold Hills (Fig. 1) and opens into the flow of the Prydz Bay gyre (Smith \& Tréguer 1984). Thus prevailing currents could bring $P$. antarcticum into Tryne Bay and Tryne Fjord. There were few and oscillating numbers of prey evident in the scats from offshore areas (Fig. 4), despite seals in offshore areas apparently being free of breeding constraints. The relatively high numbers of prey in scats from the fjords indicated that the fjord ecotypes at the Vestfold Hills were good foraging habitats, at least when they were sampled in spring and summer. Few seals were seen in these fjords during winter (S. Lake unpubl. data), which may allow the benthic prey a period in the annual cycle in which to recover from predation pressure.

\section{Mawson}

The Mawson diet was spatially homogeneous compared to the Vestfold Hills. Hypothetically, the proportion of benthic to pelagic prey should increase in shallow water because benthic prey is more accessible (Tremblay \& Cherel 2000). However the diet of seals over the shallow bank to the east of Mawson did not contain more benthic prey than the diet of seals in the vicinity of the central or western troughs (Fig. 1). The phenomena of Eckman drift (Pond \& Pickard 1983) whereby southward flowing currents reach the coast and deflect west, could be the mechanism causing spatial homogeneity in the Weddell seal diet. Alternatively, there may be overlap in the foraging areas of seals at different haul-out sites (Fig. 1). Robertson (1995) found spatial differences in the diet of emperor penguins Aptenodytes forsteri at Mawson, but this result was tentative due to small sample sizes and asynchrony of sampling.

The Mawson diet varied significantly between winter and spring, mainly with regard to the squid Psychroteuthis glacialis, which was relatively abundant in spring. Even within spring there were changes over time in the squid consumed (Fig. 6). In September, 2 size-classes were abundant in the diet, representing individuals of 3 to $20 \mathrm{~g}$ and 230 to $600 \mathrm{~g}$ body mass (Gröger et al. 2000). The larger size-class dropped out of the diet in October 1996 and November 1997. Diminishing representation of the larger size-class could have been related to changes in squid distribution, changes in seal foraging distribution, squid stock depletion by predators, or senescence of the squid after a prolonged spawning period in late winter and early spring (Lu \& Williams 1994). The 2 size-classes were probably from different habitats; small $P$. glacialis being pelagic and large $P$. glacialis having a demersal existence in deeper waters (>450 m) (Jackson \& Lu 1994). At the Mawson coast, there may be suitable habitat for large $P$. glacialis on the slopes of the underwater canyons (Fig. 2). Like prawns at the Vestfold Hills, squid was a fluctuating food source. 
Whereas prawns were small ( 2.5 g), squid were large $(\sim 100 \mathrm{~g})$ and thus a substantial additional prey source (Fig. 7) that became available to the seals around the time of pupping on the Mawson coast.

Pleuragramma antarcticum is a keystone species in Antarctic continental shelf ecosystems (Cherel \& Kooyman 1998, Fuiman et al. 2002). The abundance of $P$. antarcticum may fluctuate with environmental conditions more so than other species because it is pelagic and so utilises water column production directly (Hubold \& Ekau 1987). We found that P. antarcticum occurred in less than half the samples at Mawson despite its high abundance in the diet (Table 1). This probably reflected a clumped distribution at any point in time as shoals of this fish are known to wander slowly in and out of sampling areas (Fuiman et al. 2002) and thus be encountered episodically by the seals. Since there is high variability in the abundance of $P$. antarcticum in scats, a large sample size is required to detect temporal trends. In this study, interannual variation in $P$. antarcticum was not significant at either Mawson or the Vestfold Hills. However the comparisons were limited to only $2 \mathrm{yr}$, except in Long Fjord where $P$. antarcticum was not an important prey type. We showed that $P$. antarcticum was an important prey type at Mawson, and that spatial homogeneity in the Mawson diet would permit inference from discrete samples to the whole coastal ecosystem. Thus future investigation of temporal variation in $P$. antarcticum would be most worthwhile using Weddell seal scats from Mawson.

There was a large amount of cephalopods in the diet at Mawson, and this was consistent with the previous report of the Weddell seal diet at Mawson based on 18 scats (Green \& Burton 1987). It was also consistent with the emperor penguin diet, having more cephalopods at Mawson than at other locations in east Antarctica (Robertson 1995). In the Weddell seal diet, abundance of cephalopods was markedly higher at Mawson (82\% mass, Table 1) than at the Vestfold Hills (2\%), Larsemann Hills (2\%), and Commonwealth Bay $(10 \%)$, and at other sites around the Antarctica continent (4 to $21 \%$ mass, Plötz 1996, Castellini et al. 1992, Burns et al. 1998). The only location, apart from Mawson, where Weddell seal diet had a large component of cephalopods was the South Shetland Islands in the Scotia Arc, sub-Antarctic (91\% mass, Casaux et al. 1997). As fish predators (Roper et al. 1985, Daly \& Rodhouse 1994), cephalopods represent another level of complexity in the food web. The fish biomass in the Scotia Arc is an order of magnitude greater than is generally the case over the Antarctic continental shelf (in the Weddell Sea for example, Hubold 1991). The abundance of Pleuragramma antarcticum in Weddell seal scats (Table 1) was also evidence of relatively high fish bio- mass at Mawson, similar to the Scotia Arc. Perhaps the Mawson food web, which is relatively complex for the presence of cephalopods, is enriched by productivity advected through the deep underwater canyons from the ocean shoreward of the continental slope (Fig. 1).

\section{Regional comparisons}

There were striking differences between regions in the number of prey evident in scats. In summer, Larsemann Hills and Commonwealth Bay averaged 2 prey per scat compared to 8 prey per scat at the Vestfold Hills at the same time of year (Fig. 5). We know from species composition that the sizes of prey types taken at the Larsemann Hills and Commonwealth Bay were not larger than at the Vestfold Hills (Table 2). Thus the difference in number of prey was not accounted for by prey size. Marcus et al. (1998) showed that fasting seals have more intense digestion. Paucity of prey remains could therefore indicate that the seals were eating less food. It could also indicate consumption of soft-bodied prey, such as holotherians and salps, but we have no direct evidence for this. Considering that the seals were hauled out in dense aggregations on small areas of remnant fast ice for moulting, we suggest that the paucity of prey remains in scats from Commonwealth Bay and Larsemann Hills (Fig. 5) was a result of seals foraging less successfully at these locations.

Similarly during spring, when Weddell seals breed, the number of prey evident in scats was greater at the Vestfold Hills and at Mawson than at McMurdo Sound (Testa et al. 1985, Burns et al. 1998) or in the Weddell Sea (Reijnders et al. 1990). While non-breeding animals probably contributed to sample collections, it is unlikely that they were solely responsible, as 33 to $56 \%$ of the spring sample in this study was from pupping colonies. If breeding females were not successful in their foraging at the Vestfold Hills and Mawson then a larger proportion of scats would have had few or no prey remains. Sato et al. (2002) discuss how Weddell seals fast or forage during lactation depending on whether prey are available. Our results suggest that many seals at both the Vestfold Hills and Mawson were feeding to some extent during lactation, more than at McMurdo Sound (Hindell et al. 2002).

Plötz et al. (2001) suggested a hunting seal descending from the sea surface would not switch to benthic foraging as long as Pleuragramma antarcticum was available in the upper water column. However, travel time to the benthic foraging zone would be negligible in shallow water ecosystems. This could account for the high ratio of benthic to pelagic fish (8.8:1) in the Vestfold Hills diet. At Mawson, the lower ratio of benthic to pelagic fish (1.4:1) was in accord with a smaller 
area of neritic habitat (Fig. 2). Still, many areas of the Mawson coast are less than $200 \mathrm{~m}$ deep, and inshore benthic fish species such as Trematomus newnesi were abundant in the diet.

The prey species evident from this study were typical of the Antarctic continental shelf ecosystem. By contrast, in the Weddell Sea, seals took fish species characteristic of the continental slope (Plötz et al. 1991). At the South Shetland Islands, they took myctophids instead of Pleuragramma antarcticum, and took benthic fish typical of the sub-Antarctic islands instead of Trematomus spp. (Casaux et al. 1997). Such regional variation in diet demonstrates the flexibility of Weddell seal foraging. At McMurdo Sound, $P$. antarcticum was the main prey species (Burns et al. 1998), however, multiple prey species seem to be more typical of the Weddell seal diet. Multiple prey species and flexible species composition would minimise the coupling between Weddell seal population dynamics and the dynamics of prey species' availability (Murdoch 2002).

This study is the first report of juvenile notothenid fish $(\sim 7 \mathrm{~cm})$ and mysids in the diet of Weddell seals. Previously, small fish and crustaceans were not considered to be an important component of the Weddell seal diet. There is only 1 other report of a Weddell seal eating pelagic crustaceans Euphausia crystallorophias (Plötz 1986). Mysids are small crustaceans (5 to $10 \mathrm{~mm}$ ) that occur in dense swarms. We found mysids to occur frequently in scats at all 4 sites (Table 1) and in large quantities (up to $1 \mathrm{~kg}$ per scat) indicating that the seals were targeting mysid swarms. There is video evidence to suggest that Weddell seals pursue and capture prey as individuals (Davis et al. 1999); however, in the case of mysids the seals may capture several per mouthful. In the oceanic ecosystem, north of the Antarctic continental shelf, krill Euphausia superba and myctophids are keystone species (Eastman 1993). Our evidence of small fish and crustaceans in the Weddell seal diet reveals the potential for Weddell seals to join the oceanic community of predators that forage in the krill swarms at the southern boundary of the Antarctic Circumpolar Current (Tynan 1999).

Acknowledgements. The field work was carried out under the terms of the Antarctic Treaty Permit System and supported by Australian Antarctic Scientific Advisory Committee (ASAC). Many Antarctic expeditioners generously provided assistance in the field including B. Jones, K. Smith, and P. Delaney. L. Irvine, T. James, C. Karin and L. Wilson contributed in the laboratory. We are very grateful to Dr. S. Wotherspoon for performing the statistical analyses, further to discussions with Drs. L. Belbin and M. Haddon. We also thank Drs. N. Bindoff and R. Williams for discussions about Antarctic marine coastal ecosystems. Drs. C. Eriksson and N. Gales and 3 anonymous reviewers provided many useful comments on earlier versions of this manuscript.

\section{LITERATURE CITED}

Allcock AL, Piertney SB (2002) Evolutionary relationships of Southern Ocean Octopodidae (Cephalopoda: Octopoda) and a new diagnosis of Pareledone. Mar Biol 140:129-135

Allcock AL, Piatkowski U, Rodhouse PGK, Thorpe JP (2001) A study on octopodids from the eastern Weddell Sea, Antarctica. Polar Biol 24:832-838

Arntz WE, Gorny M (1991) Shrimp (Decapoda, Natantia) occurrence and distribution in the eastern Weddell Sea, Antarctica. Polar Biol 11:169-177

Bigg MA, Olesiuk PF (1990) An enclosed elutriator for processing marine mammal scats. Mar Mamm Sci 35:35-65

Bowen WD (2000) Reconstruction of pinniped diets: accounting for complete digestion of otoliths and cephalopod beaks. Can J Fish Aquat Sci 57:898-905

Bowen WD, Tully D, Boness DJ, Bulheier BM, Marshall GJ (2002) Prey-dependent foraging tactics and prey profitability in a marine mammal. Mar Ecol Prog Ser 244: 235-245

Burns JM, Trumble SJ, Castellini MA, Testa JW (1998) The diet of Weddell seals in McMurdo Sound, Antarctica, as determined from scat collections and stable isotope analysis. Polar Biol 19:272-282

Casaux R, Baroni A, Carlini A (1997) The diet of the Weddell seal Leptonychotes weddellii at Harmony Point, South Shetland Islands. Polar Biol 18:371-375

Castellini MA, Davis RW, Kooyman GL (1992) Annual cycles of diving behaviour and ecology of the Weddell seal. Bull Scripps Inst Ocean 28:1-54

Cherel Y, Kooyman GL (1998) Food of emperor penguins (Aptenodytes forsteri) in the western Ross Sea, Antarctica. Mar Biol 130:335-344

Clarke MR (1986) A handbook for the identification of cephalopod beaks. Clarendon Press, Oxford

Clarke M, McLeod N (1982) Cephalopod remains in the stomachs of eight Weddell seals. Br Antarct Surv Bull 57:33-40

Daly HI, Rodhouse PG (1994) Comparative morphology of two sympatric Pareledone species from South Georgia. Antarct Sci 6:163-169

Davis RW, Fuiman LA, Williams TM, Collier SO, Hagey WP, Kanatous SB, Kohin S, Horning M (1999) Hunting behavior of a marine mammal beneath the Antarctic fast ice. Science 283:993-996

Dhargalkar VK, Burton HR, Kirkwood JM (1988) Animal associations with the dominant species of shallow water macrophytes along the coastline of the Vestfold Hills. Hydrobiologia 165:141-150

Eastman JT (1993) Antarctic fish biology: evolution in a unique environment. Academic Press, California

Field JG, Clarke KR, Warwick RM (1982) A practical strategy for analysing multispecies distribution patterns. Mar Ecol Prog Ser 8:37-52

Fuiman LA, Davis RW, Williams TM (2002) Behaviour of midwater fishes under the Antarctic ice: observations by a predator. Mar Biol 140:815-822

Gales NJ, Cheal AJ (1992) Estimating diet composition of the Australian sea-lion (Neophoca cinerea) from scat analysis: an unreliable technique. Wildl Res 19:447-456

Green K, Burton HR (1987) Seasonal and geographical variation in the food of Weddell seals, Leptonychotes weddellii, in Antarctica. Aust Wildl Res 14:475-489

Green K, Burton HR, Watts DJ (1995) Studies of the Weddell seal in the Vestfold Hills, East Antarctica. ANARE Research Note 93, Australian Antarctic Division, Kingston

Gröger J, Piatkowski U, Heinemann H (2000) Beak length analysis of the Southern Ocean squid Psychroteuthis 
glacialis (Cephalopoda: Psychroteuthidae) and its use for size and biomass estimation. Polar Biol 23:70-74

Hindell MA, Harcourt R, Waas JR, Thompson D (2002) Finescale, three dimensional spatial use of diving lactating female Weddell seals, Leptonychotes weddellii. Mar Ecol Prog Ser 242:275-284

Hubold G (1991) Ecology of Notothenioid fish in the Weddell Sea. In: di Priso G, Maresca B, Tota B (eds) Biology of Antarctic fish. Springer-Verlag, Heidelberg

Hubold G, Ekau W (1987) Midwater fish fauna of the Weddell Sea, Antarctica. Proc V Congr Europ Ichthyol, Swedish Museum of Natural History, Stockholm

Jackson GD, Lu CC (1994) Statolith microstructure of seven species of Antarctic squid captured in Prydz Bay, Antarctica. Antarct Sci 6:195-200

Johnson CR, Field CA (1993) Using fixed effects model multivariate analysis of variance in marine biology and ecology. Oceanogr Mar Biol Annu Rev 33:177-221

Kirkwood JM (1983) A guide to the Decapoda of the Southern Ocean. ANARE Research Notes 11, Australian Antarctic Division, Kingston

Kirkwood JM, Burton HR (1988) Macrobenthic species assemblages in Ellis Fjord, Vestfold Hills, Antarctica. Mar Biol 97:445-457

Lake S (1997) Analysis of the diet of New Zealand fur seals Arctocephalus forsteri in Tasmania. In: Hindell M, Kemper $\mathrm{C}$ (eds) Marine mammal research in the southern hemisphere, Vol. 1: status, ecology and medicine. Surrey Beatty \& Sons, Chipping Norton, p 125-129

Lipinski M, Woyciechowski M (1981) Cephalopods in the food of Weddell seals from the Admiralty Bay (King George Island, South Shetland Islands). Polar Res 2:163-167

Lu CC, Williams R (1994) Contribution to the biology of squid in the Prydz Bay region, Antarctica. Antarct Sci 6:223-229

Manly BFJ (1997) Randomization, bootstrap and Monte Carlo methods in biology, 2nd edn. Chapman \& Hall, London

Marcus J, Bowen WD, Eddington JD (1998) Effects of meal size on otolith recovery from fecal samples of gray and harbor seal pups. Mar Mamm Sci 14:789-802

Murdoch WW, Kendall BE, Nisbet RM, Briggs CJ, McCauley E, Bolser R (2002) Single-species models for many-species food webs. Nature 417:541-543

Pierce GL, Boyle PR (1991) A review of methods for diet analysis in piscivorous marine mammals. Oceanogr Mar Biol Annu Rev 29:409-486

Plötz J (1986) Summer diet of Weddell seals (Leptonychotes weddellii) in the eastern and southern Weddell Sea, Antarctic. Polar Biol 6:97-102

Plötz J, Ekau W, Reijnders PJH (1991) Diet of Weddell seals Leptonychotes weddellii at Vestkapp, Eastern Weddell Sea (Antarctica), in relation to local food supply. Mar Mamm Sci 7:136-144

Editorial responsibility: Otto Kinne (Editor),

Oldendorf/Luhe, Germany
Plötz J, Bornemann H, Knust R, Schroder A, Bester M (2001) Foraging behaviour of Weddell seals, and its ecological implications. Polar Biol 24:901-909

Pond S, Pickard GL (1983) Introductory dynamical oceanography, 2nd edn. Pergamon Press, Oxford

Reijnders PJH, Plötz J, Zegers J, Grafe M (1990) Breeding biology of Weddell seals (Leptonychotes weddellii) at Drescher Inlet, Riiser Larsen Ice Shelf, Antarctica. Polar Biol 10:301-306

Robertson GG (1995) The foraging ecology of emperor penguins (Aptenodytes forsteri) at two Mawson Coast colonies, Antarctica. ANARE Report 138, Australian Antarctic Division, Kingston

Roper CFE, Sweeney MJ, Clarke MR (1985) Cephalopoda. In: Fischer W, Hureau JC (eds) FAO species identification sheets for fishery purposes. Southern Ocean (Fishing areas 48, 58 and 88) (CCAMLR Convention Area), Vol 1. FAO, Rome, p 117-205

Sato K, Mitani Y, Cameron MF, Siniff DB, Watanabe Y, Naito $Y$ (2002) Deep foraging dives in relation to the energy depletion of Weddell seals (Leptonychotes weddellii) mothers during lactation. Polar Biol 25:696-702

Smith N, Tréguer P (1984) Physical and chemical oceanography in the vicinity of Prydz Bay, Antarctica. In: El Sayed (ed) Southern Ocean ecosystems: the BIOMASS perspective. Cambridge University Press, Cambridge

Staniland IJ (2002) Investigating the biases in the use of hard prey remains to identify diet composition using Antarctic fur seals (Arctocephalus gazella) in captive feeding trials. Mar Mamm Sci 18:223-243

Testa JW (1994) Over-winter movements and diving behaviour of female Weddell seals (Leptonychotes weddellii) in the southwestern Ross Sea, Antarctica. Can J Zool 72: $1700-10$

Testa JW, Siniff DB, Ross MJ, Winter JD (1985) Weddell seal-Antarctic cod interaction in McMurdo Sound, Antarctica. In: Siegfried WR, Condy PR, Laws RM (eds) Antarctic nutrient cycles and food webs. Springer-Verlag, Berlin, p 561-565

Tremblay Y, Cherel Y (2000) Benthic and pelagic dives: a new foraging behaviour in rockhopper penguins. Mar Ecol Prog Ser 204:257-267

Tynan CT (1998) Ecological importance of the southern boundary of the Antarctic Circumpolar Current. Nature 392:708-710

White WB, Peterson RG (1996) An Antarctic circumpolar wave in surface pressure, wind, temperature and sea-ice extent. Nature 380:699-702

Williams R, McEldowney A (1990) A guide to the fish otoliths from waters off the Australian Antarctic Territory, Heard and Macquarie Islands. ANARE Research Note 75, Australian Antarctic Division, Kingston

Submitted: August 21, 2002; Accepted: February 18, 2003

Proofs received from author(s): May 2, 2003 